\title{
Dynamics of Approach Health Benefits of Spontaneous Engagement
}

\author{
Joseph Richard Crant \\ Canadian Psychological Association CPA \\ Ucolat Mental Health Research
}

\begin{abstract}
When it comes to approach, there is a certain amount of anxiety, apprehension, fear, and it is in this research where we have discovered something we believe is a value that attends to approach anxiety, and that leads one to participate more in spontaneous engagement/activity to produce mental emotional balance, and to enhance physical health. As a sentient being, the human being is a receptive vessel, and as a cognitive, or thinking being, it evaluates it's immediate environment via sense receptors, and responds/reacts to external stimulation drawing understanding by inference of the essence of the particular goings on of events as they occur and manifest while the vessel is in motion or subject to the movement or activity(s) of external objects. Based on 35 years of experiential research and study, in this article, I want to express my thoughts and impressions, and give testimony to something I have come to see as a phenomena, and further to suggest something vital to the existence and wellbeing of humankind has been lost, and because this work recognizes it as being inherent, suggests that it is retrievable.
\end{abstract}

\section{Introduction}

The human organism is just that, a biological organism as described by the science of biology; An organism is a living being that has a cellular structure and that can independently perform all physiologic functions necessary for life. In multicellular organisms, including humans, all cells, tissues, organs, and organ systems of the body work together to maintain the life and health of the organism [1].

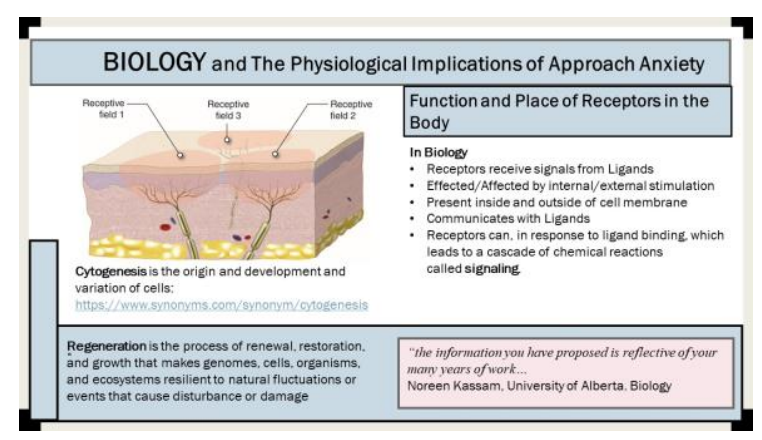

The human organism is existential, where; Existentialism is a contemporary trend in the sphere of Philosophy. It lays stress on the existence of man. Existentialism was a protest against the traditional notions of man. It purports to form a 'just' concept of man, rejecting underestimation or overestimation of Man's personality. The Chief tenet of existentialism is "Existence precedes essence" Bhandari [2] the human being is also essential. What is the meaning of all these human endeavors and activities if in the end nobody can escape death and decomposition? Man lives in the shadow of death. Whatever he may have achieved in the course of his pilgrimage, he must one day pass away and abandon all that he has built [3].

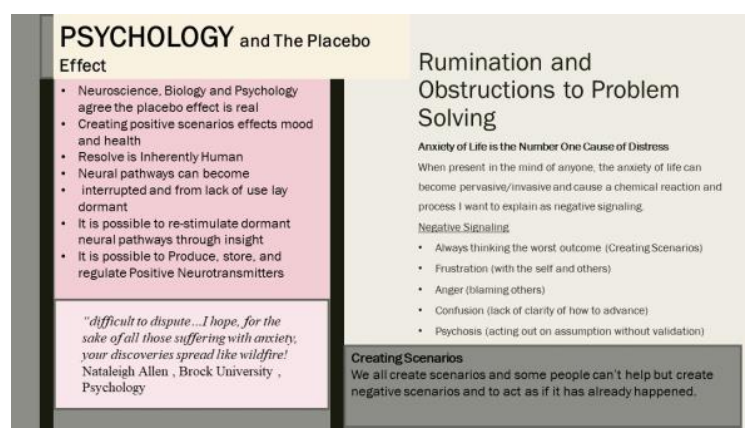

Cognitive Organism

Definition of cognitive. 1: of, relating to, being, or involving conscious intellectual activity (such as thinking, reasoning, or remembering) cognitive impairment. 2: based on or capable of being reduced to empirical factual knowledge.[4]

\section{Systemic Detoxification}

What we are talking about here is, physical manifestation from non- physical phenomena, which in science has not been discovered by or within any individual or institution organization outside of this research. Systemic detoxification is the process where the body naturally flushes toxic elements from the system and all organs fatty tissues etc. The body has natural methods of detoxification. Individual cells get detoxified in the lymph and circulatory system. Detoxification itself, is a chain of events. When a toxic molecule enters the body, it is typically sent to the liver for processing. Hence, the liver is often considered the primary organ of detoxification. Once a molecule has been processed in the liver, it is returned into circulation to be removed via the 
kidneys or through the intestines (via bile) where it is eliminated with the feces.[5]

\section{Manifestation of systemic detoxification}

Systemic detoxification related to relaxation response/phase within the body of study participants has been reported in this work and documented by journal and self reported anecdotal evidence, also, a self report we given from the author. Dr. Benson describes the Relaxation Response as a physical state of deep relaxation which engages the other part of our nervous system - the parasympathetic nervous system, Benson (1975), and it is in this "relaxation response" where manifestation of systemic detoxification occurs as the mind and body begin to relax the more the individual becomes less stressed. A note to say where an individual gains information and or insight into a phenomena be it a positive or negative experience, approach stress levels would be lesser, showing the gathering of knowledge and information and insights, to be a pivotal, and paramount factor in reducing the stress, and or anxieties of life, causing a person to be reflective and investigative, rather than reactive and responsive. This reflectiveness would, by using modern day technology and instruments, show Theta brainwave activity, and suggest/support; that where there is further investigation, familiar patterns would arise, and this is where Theta is sustainable within the psyche or psychological makeup of the individual perception model that reflects humanity, and when the views are expressed in discussions and/or during casual conversation, what is being expressed is often familiar to others, and again this would support an inherent model as natural law or moral law dictates. When we think of mental health, and what it means to be happy, because of the dictates of society, prides and prejudices of those close to us, and those that we esteem, oftentimes our perspective or view of life is not our own, as our own view, because of external information, becomes muddled. I believe it is not a far stretch to say that external information, as much of it goes against our common senses, is indeed a factor in our mental health, thus, the cause of poor mental health is where one becomes distracted from his/her true identity/perspective, and an individual can be left to feelings of detachment as conformity pacifies the human spirit.

It may be safe to assume that when we are born that we are not born a blank slate, and that nature, or God, using nature, and the laws therein, being Natural Law, we are born with a certain logic and a common sense, or perhaps it is a recognition of that which is true or the truth of a "matter at hand". This recognition of a thing would suggest further that we have a code embedded, and that as modern science would show us it is possible through the DNA to have coded information available to all living and organisms to flourish.

Psychology today will show us how learned behavior and patterning can cause some to lose their own identity, and it is obvious to anyone that many people wish they were someone else, within this research there is I believe insights and information, that you will undoubtedly agree with it is possible this other someone that we seek and desire to become, is in fact who we truly are as an individual, someone with a voice, and with value, able to make a valid contribution, whether it be an idea, an invention, a profound philosophy, a discovery, or even perhaps contributing to the care and concerns of those we meet and engage.

A few common terms we hear is; "this is the way I see it", "let me take a look at it to see what",

\section{Approach and Brain States}

Anxiety during approach is a common occurrence among many individuals, and in this paper, I hope to give insight to show how by gaining information of approach anxiety that this in fact will lessen the degree of intensity experienced during approach.

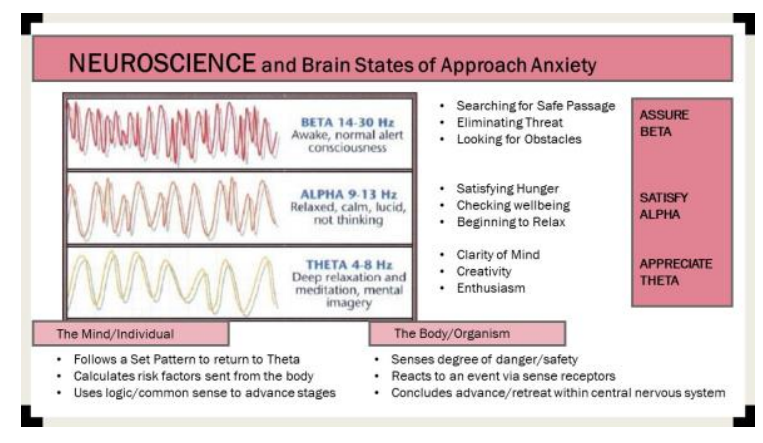

Emotional Response/Reactions

Emotional response/reaction is automatic and varies in degree of intensity with each person, and, dependent upon circumstance and situation of each event. Where an individual has prior information relating to the subject being approached, it would be understandable that anxiety and apprehension would not present a serious difficulty or a problem. A problem that many people have during approach, is a matter of trust, many people do not, and or cannot trust the source of information presented to them buy another party, and or parties, and I want to show why this is occurring, and why it is a problem that can be addressed and corrected.

\section{Overarching Paradigms}

The current overarching paradigm that exists today and that modern science, psychology, and the educational institutions have put forth, in short, has been exhausted, and we can see this is true buy a fact 
that it is widely accepted that for many years self-help authors, and motivational speakers have been regurgitating old information, and trying to present it as something new, where in fact nothing is new except where we can be presented with a newer paradigm from which to draw insight and satisfy Allen Newall's demand for a; "set of general assumptions", Newell [11], [12] to show a unified theory of cognition, a newer overarching paradigm, unified theory of cognition (UTC). Cognitive model/theory $\mathrm{C}=\mathrm{ea} 2$ is yet to be published and, is presenting itself as a candidate for such an overarching paradigm, from which science, psychology, and the educational institutions may draw insight to realise newer explanations in definition of intent, in language that is understandable and acceptable to the common lay person, and perhaps even the "self-help authors and motivational speakers.

\section{Forming an Idea}

The current insights drawn from the accepted paradigm, has given us the information being put forth and published today, humanity behaves according to this information, and it is not only presenting problems for the lay person-on-the-street, it is creating stress, and where much of it is absurdity and confusing to the laymen, it is also confusing to the educated, and the educators, everyone is affected What has been discovered and put forth by this research, is that there is within each individual, a universal perspective that is attainable, sustainable, and available to the person willing to investigate life in general from a multidisciplinary approach.

\section{Confidence and Trust in the Self}

Humanity is suffering from a lack of trust and insecurity; however, it is the lack of trusting the self and the insecurities that go along with it. As stated previous, what is missing, is a set of general assumptions, Newell [11], [12], we want to further investigate how $\mathrm{C}=\mathrm{ea} 2$ affects individuals living with, and experiencing mental health and other conditions with a focus on anxiety during approach, also to include how this cognitive model can be used to explain how spontaneous living increases the chances of longevity.

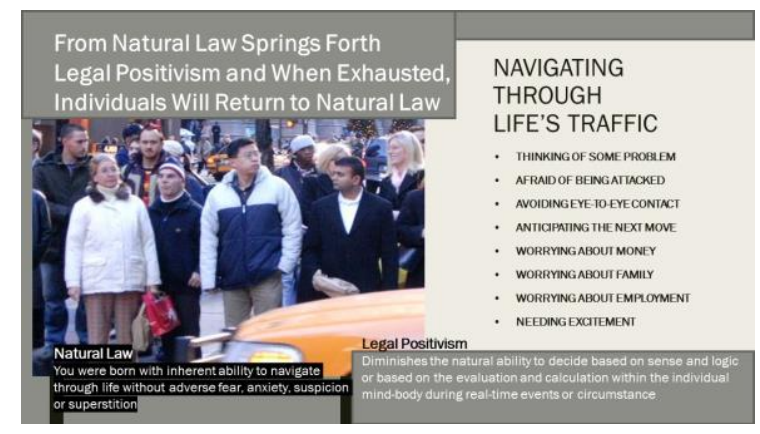

\section{Satisfying Newell's need for a set of General Assumptions}

Newell [11], [12] proposed that cognitive theories be developed in an effort to satisfy multiple criteria and to avoid theoretical myopia... Anderson and Lebiere [13], Newell's proposition could be given in advice to anyone seeking to find relief from mental health and other conditions in the sense of conducting a thorough investigation into human behavior via experiential multidisciplinary research, and study, and, the seeking after insights. In such an investigation, one would, with reference to this research, gain much to draw closer to greater health both physical and mental-emotional. Many people do not feel they have time to embark on such an intimidating proposition as it would in fact be a monumental task in scope, and the time needed cannot be guaranteed to fulfill and complete the study and to see-it-to-the-end, of which and ending would be illusive. With that in mind, the time needed to achieve satisfactory results can be reduced to a few weeks, to a few months where the individual gains an accurate understanding and an acceptance of this Cognitive Model/Theory $\mathrm{C}=\mathrm{ea} 2$.

\section{Personal Perspectives}

Most, if not all adults have a personal perspective that is developed over the course of a number of years, experiencing life first-hand and through trial and error, but many do not cultivate their own view as many are influenced by another person or an institution/organization, or group affiliate.

The human brain can become systemized through conforming to the dictates of a society, and, the thinking process itself can become retarded and resemble theoretical myopia, as describe by Anderson, Lebiere [13]; "The Newell Test for a theory of cognition".

Struggle and strife creates feelings of despair in some individuals, and resilience and creativity in some others, so a problem to address would be; how to motivate an individual to remain optimistic during hardship, and, how do we inspire a person to want to seek insights consistently and to grow by experience through trials and tribulations? The world has had many "self-help authors" and "motivational speakers", and who can count the number of new authors and speaker that have recently stepped out and made an effort to assist people with decision making and so much more in the way of gaining wholeness. All people have the same opportunity to seek out information and to develop a healthy perspective, but many choose not to, and therefore they will accept the advice of someone they esteem intelligent and or one that claims to have some "magic bullet" that is going 
to immediately change their life for the better, real life is not like that, we have to dig in and do-the-work'

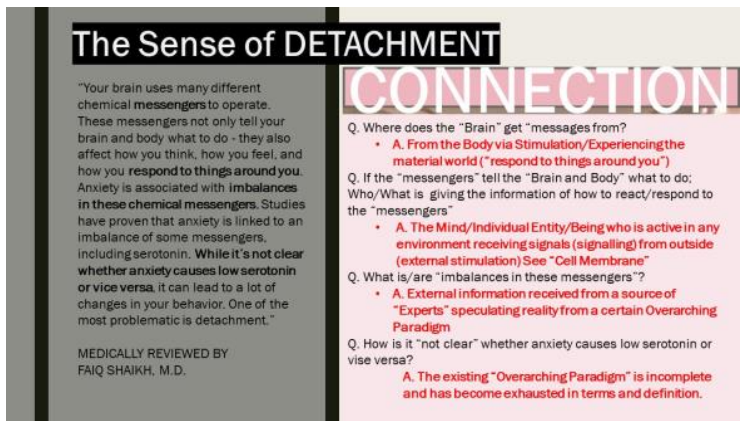

The Autodidact-Self Learning

The self-learning route can only become a success after many years of researching and study, and through life experience, however, without an acceptable paradigm from which to draw insight, one can only hope to gain something from the effort, alas, $\mathrm{C}=\mathrm{ea} 2$ offers multiple perception models from which to draw insight and gain a more accurate understanding of behavior as it is based in natural law or "moral law", which is believed by many scientists to be inherent; Natural law, in philosophy, a system of right or justice held to be common to all humans and derived from nature rather than from the rules of society, or positive law. ... In contrast, the Stoics conceived of an entirely egalitarian law of nature in conformity with the logos (reason) inherent in the human mind.[6] It is by gaining an adequate understanding of $\mathrm{C}=\mathrm{ea} 2$ that can lead a vested person to regain a moral compass that was lost to Positive Law, and instruction or from "external information that is often given in advice.

\section{Developments and Deliverables}

This research has produced a volume of information and insights that are available for the development of more programs designed to assist in the relief of anxiety and other forms of mental health matters. $\mathrm{C}=\mathrm{ea} 2$ has produced anecdotal evidence and testimonials [7] that suggest and support the notion that all humans are born with certain qualia that; philosophers who hold or have held that there are qualia, in this sense of the term, include, for example, Nagel [14, Peacocke [15] and Block [16], and that, this innate notion to think "outside-of-the-box", can become a "knowing" and lend a personal perspective rightly suited to sustain Theta and or a consistent source of creativity.

\section{Further Research Investigation and Funding}

This research was solely funded by the author and it is the hope of the author that an interest in this work will follow publication and that funding and collaboration becomes available to develop more educational programs designed to assist all people in their pursuit for better health.

35 years of experiential research and informal study has led to the development of cognitive model/theory $\mathrm{C}=\mathrm{ea} 2$, and produced systemic detoxification in induvial case study, documented and published in international journal for the viewing of interested parties. [7]

\subsection{On the Science of the Mind}

\section{Nathan B. Albright}

The area of the mind has long been an area that has gotten philosophers and scientists in a flummox. Our current popular scientific worldview insists on a materialistic world that excludes the existence or relevance of any nonmaterial factors. For the consistent philosophical materialist, therefore, the mind must not have any existence that cannot be limited or defined in the brain. That is to say, only electrical or mechanical or chemical actions of the brain are real. That which is spiritual, or moral is merely an epiphenomenon, in that view.

Therefore, the problem for philosophers of mind is how can one deal with the physical consequences of non-physical phenomenon. The rapid rise of the diagnosis and (apparent) prevalence of mental illness suggests strongly that physical and mental processes have strong connections. For example, physical behaviors (like sex, drug use, and alcoholism) have an effect on the way the brain works. Additionally, anxiety and depression, which are psychological disorders have physical consequences and complex causes, some genetic and some environmental. This would imply that a philosopher of the mind who wished to deal with the moral issues of our thoughts and ruminations would have a relatively free reign to posit grand theories about how the mind works relating the physical and the mental together. [9]

\subsection{On the Process of Mental Thermodynamics}

Nathan B. Albright

A little while ago I commented briefly on the Theory of Mental Thermodynamics, the brainchild of Joseph Richard Crant. Let us comment again on this subject so that we may understand his view of the process of mental thermodynamics, and also examine 
where the process may break down, causing problems. Specifically, let us examine how abusive and intrusive events such as trauma may lead paradoxically to mental growth but also to great stress on the mind. An understanding of this paradox can help us understand how some creative people (writers and musicians, for example) can be strong in some parts of mental health and weak (or "troubled") in others.

According to the theory of Mental Thermodynamics, all events are singular and "absurd," and the mind saying "no" to the experience is what begins the process of internal dialogue. This first state of mental thermodynamics is "chaos," the state where one's internal perception of reality is violated by external reality. In particular, let us note that events which disturb the mind's internal equilibrium are likely to be perceived as traumatic. These could be experiences in warfare, dealing with rape or sexual abuse, the death of a relative, the loss of a job, or any event which is seen as unjust and unfair. Therefore, at the base of mental thermodynamics we have the traumas of life, some of the relatively "ordinary," and some of them deeply troubling on multiple levels. The traumas of our life give us the raw material for mental (and spiritual) growth but also the seeds of great psychological trouble. Handled well, they can make us far stronger and wiser than we could be normally. Handled poorly, they can cripple us physically, mentally, emotionally, and spiritually. More often we can handle some aspects better than others, and so we show some elements of great strength and others of great weakness.

Once the mind accepts the reality of the trauma (and is no longer in denial or shock) the second state of mental thermodynamics begins. This state is called entanglement, and it represents the physicalemotional sense response to the traumatic event. These feelings are often very intense, and very mixed. There are a host of dangers attached to this stage. If the feelings are too overwhelming, the intensity of grief may actually shut down the body and mind's ability to cope or process the overwhelming feelings. This walling away of emotions can cause long-term and crippling damage to not only the person (which may be manifested in an increase of blood pressure, crippling migraine headaches, autoimmune difficulties like chronic fatigue or Morgellons, and eventually death by heart attacks or strokes) but also to the person's abilities to make and form lasting relationships with others. Additionally, problems can result if the person decides to cope with the trauma by becoming less sensitive to the world around, which can cause dangers from a lack of ability to recognize and respond to threats. When trauma comes from the family, children in particular may feel it is too dangerous to recognize the permanent state of threat and thus engage in doublethink and denial strategies to cope with the constant danger without having to think about it. This refusal to ruminate - to struggle with the reality - prevents mental growth and healing from occurring because it shuts off the possibility of accepting reality. This is the first gate that must be passed to lead to restoration of equilibrium and contentment.

Once the mind has passed that gate and committed itself to wrestling with the problem, the third state, or commitment, is reached. In this state the mind wrestles over and over again with the problem seeking to defeat it by understanding it. The mind mulls over various ways of dealing with the problem in an internal debate, seeking to understand the reason and the purpose for it all. There are a few dangers in this stage of dealing. For one, the mind can be exhausted in dealing with it and loses commitment to keep wrestling, which forces the mind back on the previous gate's problem of denial. Another difficulty is that at this stage the pain of dealing and wrestling with the problem is very acute - there are often very serious and very unpleasant implications of one's ruminations, and often people try to dull the pain by medicating it away with alcohol and drugs, or distract it away with work or pleasure addictions. This leads to other abuse problems that merely complicate the initial one. It is at this stage that one finds many activists and writers - wrestling publicly and openly with their problems, without resolution but also without trying to escape from the force of the trauma or the ugly questions it raises.

The fourth state is rest. This state is reached when the mind finds closure or acceptance of the truth and gains insight from the trauma. No longer is it a raw wound sensitive to the touch, but it is a pearl of great price formed from the intrusive sand that for so long troubled the heart, mind, body, and spirit of the person. Through much (hard) work the mind reaches contentment and acceptance and there can be the enjoyment of wellbeing and health, as the trauma is no longer causing collateral damage. To reach this state, with any trauma, is to gain an accomplishment of making sense of what happened and putting it in its proper place. Once it troubles the mind no more, the mind can reach a new equilibrium. Many people fail, for whatever reason, to reach this point. Nonetheless, this is our goal with each trial and each trauma that we face in our lives.

This model provides a reason why some people may show up better on some measures of mental health than on others. For example, those who remain sensitive and responsive to the outside world will show up as being more "open" than those who have shut themselves off from painful and unpleasant realities. They will correspondingly show up as healthier. Those who ruminate on the unpleasant aspects of life, like oysters trying to keep the sand at the core of a pearl from bothering them, will show up as healthier than those who engage in doublethink or 
other strategies of self-deception. However, until acceptance and closure is reached, all of those people will show some (perhaps serious) measures of mental and emotional stress as well. Perhaps they will be wrestling with chronic depression, or PTSD, or some other such disease.

This particular model offers some major conceptual possibilities, as well as the chance to quantify the "work" of the mind in terms of thermodynamics, allowing what has been until now a very nebulous and vague field to be quantified. There are a few questions that would need to be answered before such a theory could be seen as verified, at least in part. For example, what is the picture of a mind in each state? What parts of the brain are working and active during the states of chaos, entanglement, commitment, and rest? How can one quantify how strong a trauma is, or how "entangled" (or sensitive) someone is to their outside surroundings? How can one quantify how much work a brain does to ruminate about an unpleasant subject so that it can be understood? These tasks remain to be solved, and until they do mental thermodynamics will remain an interesting concept, but not something that can be seen as scientifically verified. Nonetheless, they remain at least within the realm of possibility of verification or falsification, or of tweaking in case it should be necessary to add other terms [10].

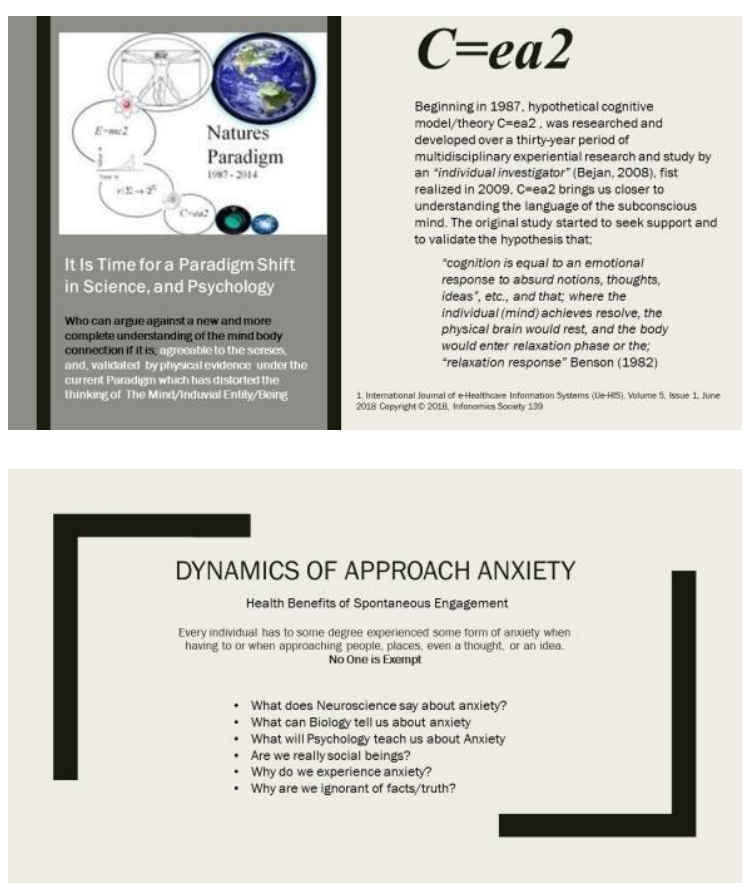

\section{References}

[1] Lument Learning, https://courses.lumenlearning.com, (Access date: 12 March 2018).
[2] Bhandari, D.R., Existentialist Perception Of The Human Condition: With Special Reference To Sartre. Contemporary Philosophy. https://www.bu.edu/wcp/ Papers/Cont/ContBhan.htm, (Access date: 1 April 2019)

[3] Mises Institute, https://mises.org/library/essentialproblems-human-exis tence, (Access date: 14 March 2019).

[4] Merriam-Webster, https://www.merriam-webster.com/ dictionary/cognitive, (Access date: 12 February 2018).

[5] FX Medicine, https://www.fxmedicine.com.au/blogpost/organs-detoxification, (Access date: 1 February 2018).

[6] Encyclopædia Britannica, https://www.britannica.com/ topic/natural-law, (Access date: 10 January 2018).

[7] The Language of Essence and Inference in Mental Health: Natural Law, Legal Positivism-Cognitive Dissonance: International Journal of e-Healthcare Information Systems (IJe-HIS), Volume 5, Issue 1, June 2018

[8] Stanford Encyclopedia of Philosophy, https://plato.stanford.edu/entries/qualia/, (Access date: 15 December 2017).

[9] "On The Science Of The Mind", Edge Induced Cohesion, https://edgeinducedcohesion.blog/2011/07/27/ on-the-science-of-the-mind/, (Access date: 14 December 2017).

[10] "On The Process of Mental Thermodynamics", Edge Induced Cohesion, https://edgeinducedcohesion.blog/2011/ 08/07/on-the-process-of-mental-thermodynamics/, (Access date: 3 March 2018).

[11] Newell, A., (1980) Physical symbol systems. Cognitive Science 4:135-83. [arJRA, WJC, PAMG, SS].

[12] Newell, A., (1990) Unified theories of cognition. Harvard University Press. [arJRA, WJC, PAMG, WDG, AGBtM, SS, HW, RMY]

[13] Anderson, J.R., Lebiere, C., (2003). The Newell Test for a theory of cognition. Behavioral and Brain Science, 26, 587-640.

[14] Nagel, T. (1974). What is it like to be a bat? Philosophical Review83(4), 435-450.

[15] Peacocke, C., (1983). Sense and Content. Oxford: Oxford University Press.

[16] Block, N., (1990). Inverted Earth. In Philosophical Perspectives, Vol 4, Ed. James E. Tomberlin, 53-79. Atascadero, Calif.: Ridgeview.

\section{Acknowledgements}

I would like to say a big "Thank you" to my wife of 37 years, Tina, for the support and for the patience that she has shown me over the course of many years of my studying and often times leaving her alone to 
International Journal of e-Healthcare Information Systems (IJe-HIS), Volume 6, Issue 1, June 2019

herself. Nathan Bennett Albright, for contributing so much of his time and for giving permission to add some of his own words in support of this work. 